\title{
Changing and pivoting the business model in software startups
}

\author{
João M. Fernandes and Paulo Afonso \\ ORCiD 0000-0003-1174-1966 and 0000-0003-3882-2491 \\ Email: jmf@di.uminho.pt and psafonso@dps.uminho.pt \\ Dept. Informática and Dept. Produção e Sistemas / Centro ALGORITMI \\ Universidade do Minho, Braga, Portugal
}

\begin{abstract}
Summary. In a company, its business strategy and business model undergo changes throughout its life. These changes can be induced or forced externally or they can result from a deliberate strategy to improve the business performance and to achieve success. Certain changes can lead to a major change in the business model of the company (i.e., a pivot). Such change or innovation in the business model can occur in various of its dimensions. According to Osterwalder and Pigneur, there are four epicenters of change and innovation to be taken into consideration. In this manuscript, fifteen Portuguese software startups were studied using essentially semi-structured interviews to gather the information. The data was processed with a software application for qualitative data analysis. The main results are related to a dynamic process of evolution and change of the business model in software startups. In particular, we have identified that the changes in the business elements that support the production of the value proposition (left-hand side of the Business Model Canvas) affect the elements that explain the strategy of delivering the value proposition to customers (right-hand side of the Business Model Canvas).
\end{abstract}

Key words: software companies; startups; business model; strategic innovation.

\section{Introduction}

The business strategy and business model undergo changes throughout the company's life, in order to improve its performance and success. For example, the difficulty in gaining customers can lead to a major change in the business model of a company (i.e., a pivot). A pivot is a special change designed to test a fundamental new hypothesis about a product or business model and assumes itself as an important engine for growth and consolidation of the business [1]. Pivots can be interpreted in a broader way considering, not only radical or high-impact changes, but also more specific or incremental changes that are gradually changing the company's course and the configuration of the business. Since pivots have a significant impact on the business model of the company and on its success, it 
is important to understand this phenomenon. Unfortunately, the literature still offers few contributions about this topic.

Terho et al. [2] studied how pivots can change business hypotheses. Their work includes three case companies (all small software startups from Tampere, Finland) and map the pivot effects on the business hypotheses. They found out that the pivots can be identified by changes in the Lean Model Canvas and that pivots usually occur in groups.

The study conducted by Bajwa et al. [3] focused on understanding the pivoting processes of software startups and on identifying the triggering factors and pivot types. Their initial results show that the pivots are triggered by various factors, namely negative customer feedback.

Osterwalder and Pigneur highlight four epicenters of change and innovation in the business model [4]. Voelpel et al. suggest a systematic structure for the reinvention of the business model, thus enabling entrepreneurs to evaluate the business models of their companies [5]. The change in the business model is also presented in the literature in the context of strategic innovation. Entrepreneurs have to decide, at the strategic level, three basic questions [6]:

- Who will be the customers?

- What type of products/services should be offered?

- How products/services should be offered in an efficient way?

Osterwalder and Pigneur also add the question "how much", which expresses how much a company can get profits from its products/services [4]. Thus, according to these authors, the business model can be divided into four pillars (who, what, how [7], and how much), and each of them can be translated into a main element of the business model. These four pillars can be translated into four main business model elements that can then be further decomposed [8]:

- Product elements: a company's value proposition;

- Customer relationship elements: how a company comes into contact with customers and what kind of relationships it wants to establish with them;

- Infrastructure management elements: type of activities, resources, and partners needed to provide the product elements and customer relationship elements;

- Financial aspects elements: revenue streams and pricing mechanisms for a company, i.e., how the company makes money through the other three elements.

In this manuscript, fifteen Portuguese software startups, all located at Braga, were studied using essentially semi-structured interviews to gather the information. The data was processed with NVivo, a popular software application for qualitative data analysis.

The remainder of this paper is structured as follows. A description of the Business Model Canvas (BMC) is given in Section 2. Some issues related to business change and innovation is discussed in Section 3. Section 4 presents the 
research methodology. In Section 5, the major results of this study are analyzed and discussed. Finally, section 6 concludes the paper and presents some opportunities for further work.

\section{Business Model Canvas}

A business model describes the logic of creating, delivering and capturing value by an organization [4]. It must be simple, clear and easy to understand, but not too oversimplifying the complexity of the functioning of a particular company. By addressing, in a conceptual way, the business model, it can be harnessed, modeled, understood, shared, observed, measured, and simulated.

Stähler considers business models as a new analytical unit for innovation [9]. Indeed, the business model can be seen as a way to tell a good story, aiming to align employees on the type of value to be created in a particular company.

Many authors have proposed different models for addressing the business of a company. For example, Alt and Zimmermann [10] consider the six following business elements. Mission: A critical part of the business model is developing a high-level understanding of the overall vision, strategic goals and the value proposition including the basic product or service features. The Structure determines the roles of the different agents involved and the focus on industry, customers and products. Processes provide a more detailed view on the mission and the structure of the business model. Revenues are the "bottom line" of a business model. Legal issues influence all aspects of the business model and the general vision. Technology is an enabler and a constraint for IT-based business models. Also, technological change has an impact on the business model design.

This manuscript considers the popular Business Model Canvas (BMC), proposed by Osterwalder and Pigneur [4] that consists of nine components as shown in Fig. 1:

- Value Proposition (VP): It should focus on the problem that will be solved, in the needs that customers want to see satisfied and, in the products, and/or services to offer to each segment of customers.

- Customer Segments (CuS): Customers are grouped in different segments according to their needs, behaviors, and other specific attributes.

- Channels (CH): Through channels of communication, distribution and sales, companies reach their customer segments and deliver the value propositions.

- Customer Relationships (CR): Relationships (personal and automated) between a company and its customers.

- Revenue Streams (RS): Set of forms of business monetization.

- Key Activities (KA): activities that support the value creation process inherent to the business model.

- Key Resources (KR): Main resources (e.g., human, physical, technical) that support the main activities. 
- Key Partnerships (KP): Suppliers and company partners that contribute to the optimization of the business model and to the reduction of business risks.

- Cost Structure (CoS): Implies recognizing and understanding all the costs involved in the business operation.

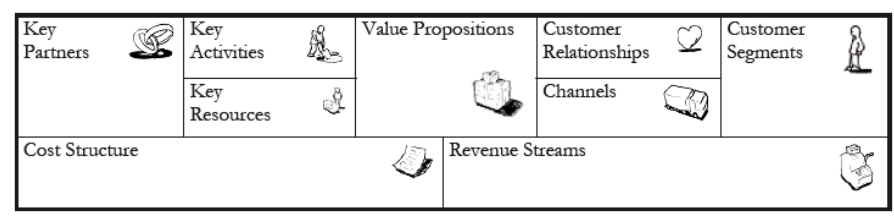

Fig. 1. Business Model Canvas [4].

This model, used and tested whole over the world, was used during this study and the components that comprise it cover the four most relevant areas of a given business: customers, supply, infrastructure and financial viability.

Some studies refer to BMC and connect it with other models. Cann et al. suggest the use of a model for software entrepreneurs to help startups to succeed and survive in the initial phases [11]. This model, called Early-Life Decision Model (ELDM), identifies 17 different types of decisions that can be taken in a daily basis at companies in order to achieve market success. These types of decisions are grouped into four major dimensions (shaping the company, developing the product, establishing the market, and going international), and 12 of the identified decision types may be contained in the BMC. Some types of decision can be placed on more than one BMC component, and some components may contain more decision types in a particular category than others.

\section{Business Model Change and Innovation}

In order to remain viable on the market, a company may need to change its business model over time.

Osterwalder and Pigneur claim that each of the nine components that are part of the BMC can be a starting point to innovate the business model of a company [4]. They also consider four epicenters that can be starting points for the innovation of business models:

- Resource-driven epicenter: This type of epicenter allows to expand or transform the business model of the company, through the innovations originated in the company's infrastructure or through a partner.

- Offer-driven epicenter: Innovations from this kind of epicenter create new value proposals to be delivered to the customer. The emergence of these new value proposals therefore alter the other components of the business model. 
- Customer-driven epicenter: These innovations are based on the needs of each client, in the facilitated access or in the increase of the convenience.

- Finance-driven epicenter: The innovations of this type of epicenter arise from finance, pricing mechanisms or from reduced cost structures.

These four types of innovation epicenters of the business model are important mechanisms for a better understanding of the components where changes can occur and the components that will be affected by them. In any case, all the innovations that depart from resources, value proposition, customers, and the financial dimensions affect the other components of the business model.

Linder and Cantrell interviewed 70 business executives and analysts, and their study aimed to identify a roadmap for operations managers to lead the change in their business models [12]. This study presents a list of 39 different ways to change the business model, ranging from narrowing or expanding the target market to changing the production of products for services.

Voelpel et al. suggest a systematic structure for the reinvention of the business model, thus enabling entrepreneurs to evaluate the business models of their companies [5]. After conducting a literature review on the subject, these authors found that there has been little guidance on how to remodel business models. The reconfiguration of the business strategy and the dynamic capabilities of the company are some of the factors contributing to the development of a new business model.

As a result of this study, a wheel-based model was developed to illustrate the reinvention of the business model (Fig. 2). This wheel allows entrepreneurs to know how to operationalize and measure the development of new business models. It presents the interactive (systemic) flow of the four dimensions in the reinvention of the business model: (1) customers; (2) technology; (3) business system infrastructure; and (4) economics/profitability. The wheel allows companies to continuously try to reinvent themselves, iterating the process throughout the four dimensions.

In many cases, for companies to survive and succeed in the market, they must be able to change the business strategy during their lifecycle.

Among the different types of strategies, one can highlight the growth strategy. The following approaches can be followed by a given company [13]:

- It can acquire companies in a distribution channel, thus approaching the final consumers of its products (vertical integration);

- It can acquire competitors, thus increasing not only its size, but also its sales volume and its market share (horizontal integration);

- It can diversify its business;

- It can merge with another company, causing them to become just one.

Growth strategies can be divided in four types [14]:

- Innovation: Some companies are concerned with constantly innovating their products/services, to allow them to keep ahead of their competition;

- Internationalization: By entering into the markets of other countries, some companies can grow and increase their sales volume; 


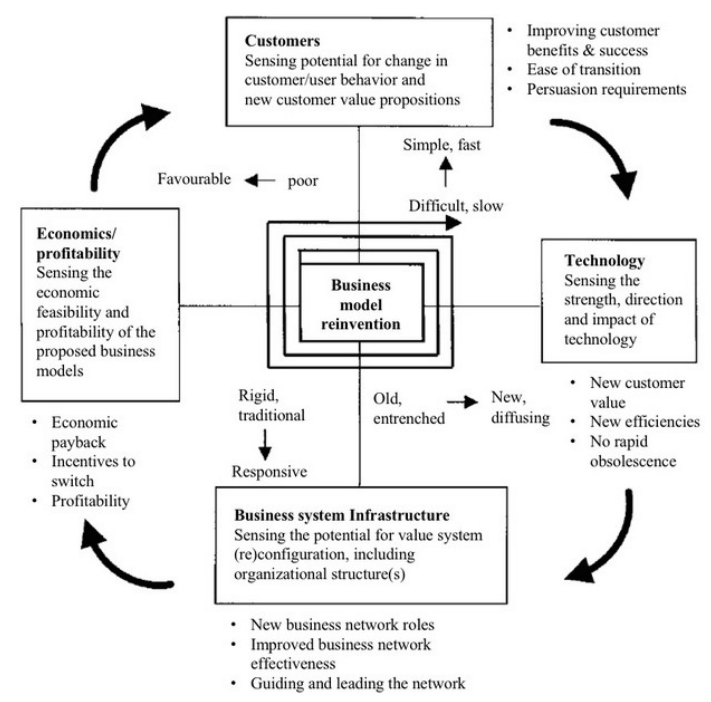

Fig. 2. Reinventing the business model [5].

- Joint venture: Two companies can join for the development of a product to be placed on the market;

- Expansion: Some companies are looking to expand their business in the market segment where they currently operate.

Several authors refer various types of strategies that can be adopted, contributing to the growth of the business. According to Markides [7], "strategic innovation occurs when a company identifies gaps in the industry positioning map, decides to fill them, and the gaps grow to become the new mass market". These gaps can be interpreted as customer segments, needs that they seek to see supplied or new forms of production, delivery or distribution of products/services. A company can develop, proactively and in an organized way, a new business model: redefining the WHO, redefining the WHAT, redefining the HOW. Additionally, answers to the three key questions should be obtained: (1) who should be selected as a client? (2) what products/services and value propositions we offer to the selected clients? (3) how to offer these products/services in a cost-efficient form? [7].

Ries considers that the strategy that a startup applies must include a business model, a product road map, a perspective about partners and competitors, and ideas about the characteristics of the customer [1]. This strategy has as a final result the product to be developed by the startup in its first years of existence.

\section{Research methodology: Semi-structured interviews}

This section describes the research approach followed during the study reported in this manuscript. The semi-structured interview was the method selected for 
the collection of the data in the different companies involved in this study, because it presents adequate characteristics for the purpose of this research.

The interviews must be well organized and structured in order to obtain quality data, and they can take place in four key steps: (1) identification of the interviewees; (2) preparation of the interview; (3) conducting of the interview; and (4) conclusion [15]. These four steps were carried out in the interviews conducted in this study.

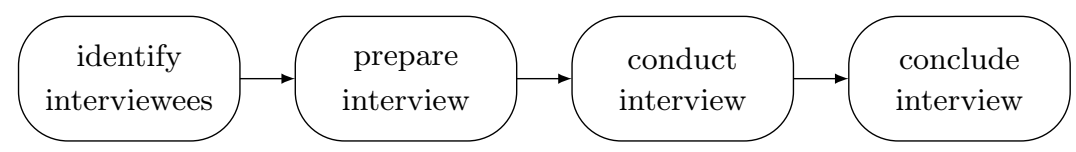

Fig. 3. Main steps of an interview.

The semi-structured interview was used as a way to gather the data for this study. A characteristics of this type of interview is the use of a previouslyelaborated guide [16]. A guide offers to researchers support at the time of gathering verbal data in the interviews they perform. The semi-structured interview combines the features of structured and unstructured interviews. In this type of interviews, it is necessary for the interviewer to create a certain dynamics and to control the way how the interview takes place.

Interview script The interviewer needs to prepare some key questions to be asked during the interview. The interview script was elaborated based on the BMC and the ELDM. During its elaboration, the script was changed several times, so that the questions were placed in the most appropriate order, were not ambiguous, and permitted the interview to not exceed 60 minutes. The guide used for the interviews in this study was structured as follows:

\section{General information}

1.1 Information about the interviewee (education, role, experience)

1.2 Information about the company (location, size, business)

2 Business modeling and market entry

2.1 How the company was initially modeled (mission, vision, staff)

2.2 Product and market (initial product, initial market)

2.3 Market entry strategy

2.4 Internal and external restrictions

3 Business growth strategy

3.1 Key moments in the business growth

3.2 Evolution in the value proposition

3.3 Changes in the relationship with the market

3.4 Changes in the business model

4 Economic-financial issues

4.1 Cost structure and revenue streams

4.2 Investment, funding, and profitability

4.3 Business management 
Planning the interview At this stage, (1) the inclusion criteria were established, (2) the interview script and the confidentiality document were edited, (3) a pilot interview was conducted to identify the aspects to be corrected/improved in the script and to better prepare the conducting of the interviews, (4) the companies that could be considered in the study were identified, and (5) the contacts with the companies were established.

Interviewees This study was conducted in Portuguese software startups, all with their headquarters in the city of Braga. The 15 companies that agreed to cooperate in our study were categorized in three different groups, based on their value propositions (i.e., the type of software systems they develop). In this study, each category includes five companies classified as:

1. Own projects (OP): development of the portfolio's own projects, i.e., the company takes the initiative to develop its own software (mass-market) products, platforms and/or mobile applications;

2. Bespoke projects/services (BP): development of applications/systems tailored to customers;

3. Own projects and bespoke projects/services (OP\&BP): this group includes companies that simultaneously address the two previous profiles.

A summary of the companies, anonymously designated from $\mathrm{A}$ to $\mathrm{O}$, is provided in Table 1. Among the 15 collaborators (i.e., one per company) that were available to be interviewed, 13 held the position of CEO and the remaining two were CTOs. Only two of these 15 persons were not co-founders of the companies. Although it was not possible to meet with a co-founder in these two companies, the CEOs had a good knowledge about the company history and its evolution from the beginning of their activities. In some cases, additional questions were asked during the interviews, according to the answers that were provided.

Interview analysis This phase was characterized by the transcription of the interviews, production and validation of the reports. For each interview, the respective transcript was made (except in one case, since the CEO did not allowed the interview to be audio recorded). During the transcription, when new questions arose or when some issues required further clarifications, the interviewee was contacted again. When the transcript of each interview was considered as complete, it was sent to the interviewee for validation.

The data standardization was carried out iteratively. The process was stopped when we got adequate conditions for coding the interviews and analysing in the NVivo program (software for qualitative data analysis). The use of the NVivo program proved essential for this work, as it allowed us to group the data into topics and to identify similar aspects among the participating companies.

\section{Analysis and Discussion}

The main results and findings of this study are discussed in this section, namely the most relevant aspects related to the building blocks of the BMC and how 


\begin{tabular}{|c|c|c|c|c|c|c|}
\hline \hline Cpy. & $\begin{array}{c}\text { Found. } \\
\text { Year }\end{array}$ & Category & Workers & Turnover & Interviewee & Date \\
\hline A & 2012 & OP\&BP & 11 & 500 & CEO & May \& Aug 2016 \\
B & 2011 & BP & 11 & 250 & CEO & May \& Jul 2016 \\
C & 2012 & BP & 10 & 200 & CEO / co-founder & May 2016 \\
\hline D & 2011 & OP\&BP & 17 & $\mathrm{n} / \mathrm{a}$ & CEO / co-founder & May 2016 \\
E & 2010 & OP & 12 & 1.000 & CTO / co-founder & May 2016 \\
F & 2008 & BP & 15 & n/a & CEO & May 2016 \\
\hline G & 2013 & OP & 8 & n/a & CEO & Jun 2016 \\
H & 2008 & BP & 7 & 180 & CEO / co-founder & Jun 2016 \\
I & 2013 & OP & 7 & 50 & CEO / co-founder & Jun 2016 \\
\hline J & 2011 & OP\&BP & 8 & 170 & CEO / co-founder & Jun 2016 \\
K & 2013 & OP\&BP & 3 & 50 & CEO / co-founder & Jun 2016 \\
L & 2013 & BP & 11 & 560 & CEO / co-founder & Jun 2016 \\
\hline M & 2013 & OP & 6 & 50 & CEO / co-founder & Jul 2016 \\
N & 2011 & OP\&BP & 14 & 1.200 & CEO / co-founder & Jul 2016 \\
O & 2014 & OP & 9 & 0 & CTO / co-founder & Aug 2016 \\
\hline \hline
\end{tabular}

Table 1. Characterisation of the companies. Turnover refers to 2015 and is presented in thousands of Euros.

they changed and evolved in the considered startups. The key moments and the decisions in terms of business model change are also highlighted.

\subsection{Results}

By analyzing how each of the nine BMC components have changed between the key moments that characterize the life of each company, one was able to identify which one had the highest number of changes. A score, ranging from zero (minimum score) to three (maximum score), was established to measure the change level of the BMC components (see table 2).

\begin{tabular}{|c|l|}
\hline & Meaning \\
\hline & The BMC component had ... \\
Zero & $\ldots$ not undergone any major changes \\
One & $\ldots$ few and small changes \\
Two & $\ldots$ significant changes \\
Three & $\ldots$ completely changed (pivot) \\
\hline
\end{tabular}

Table 2. Score assigned to the change in the BMC components.

Fig. 4 and 5 summarize the main results of business model change in the 15 companies that were studied. In Fig. 4 we can see how each component of the business model of each company has evolved or changed ranging from white (no relevant changes were identified) to dark blue (when pivoting or radical change was found). Fig. 5 presents the number of changes by component in the three 
types of companies and in aggregate. The dimension or the level of change is indicated by the accumulated points in each building block of the business model canvas.
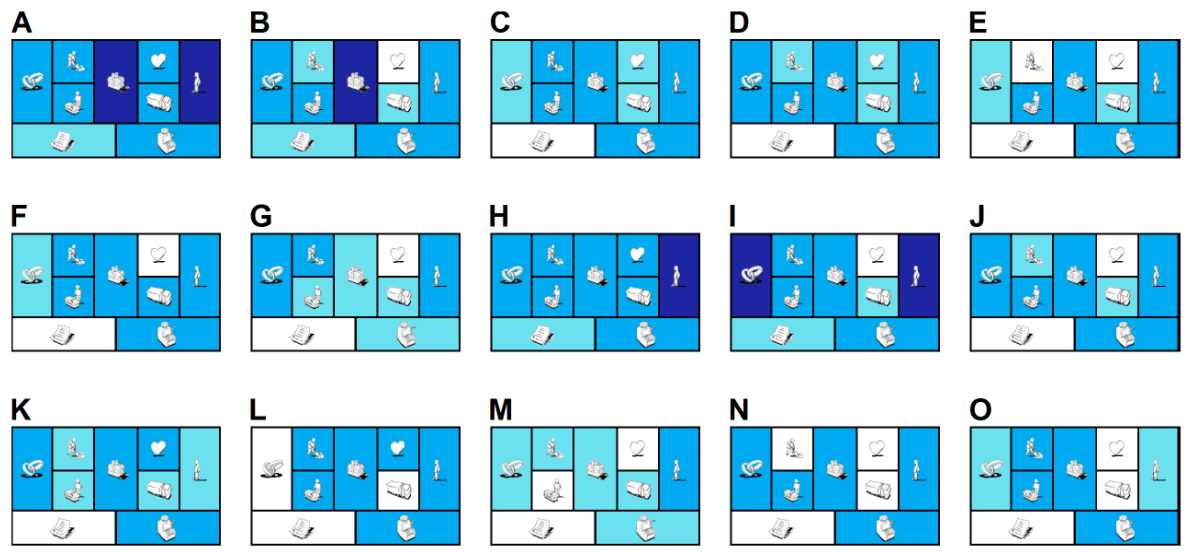

Fig. 4. Scores assigned to measure the change in all BMC building blocks for each company. Dark blue $=3 ;$ blue $=2$; light blue $=1$; white $=0$.

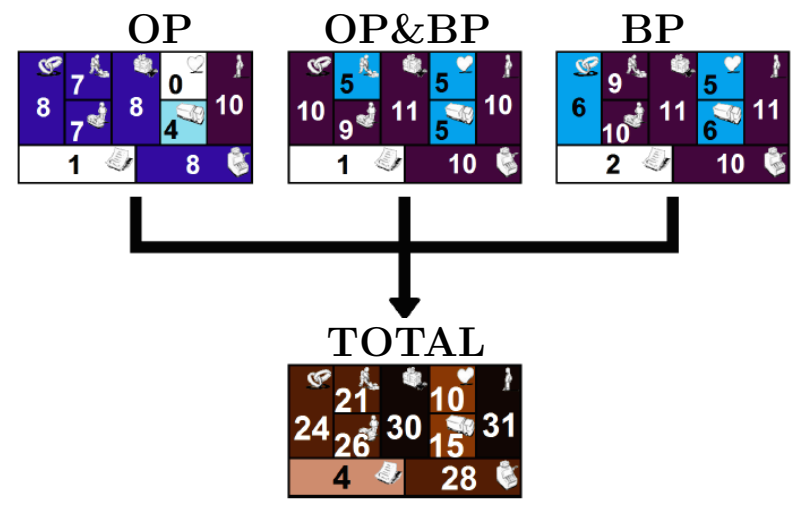

Fig. 5. Scores assigned to measure the change in all BMC building blocks for the three types of companies (OP, OP\&BP, BP) and in aggregate (TOTAL).

\subsection{Discussion}

These results corroborate some assumptions found in the literature (e.g., Osterwalder and Pigneur's epicenters of change [4] and the three dimensions of strategic innovation suggested by Markides [7]), but also give new insights on this process. Taken into consideration the exploratory nature of this research, these findings ask for further validation through in-depth case studies or a survey 
approach but they offer already interesting and additional issues for discussion. Some of these findings are discussed below.

\section{The most stable components in the BMC}

In the companies considered in this study, most of the components of the business model changed but some did not show relevant changes. It is the case of the CoS building block in the left-hand of the BMC. Apparently, software startups may evolve and change during the first years of life but such changes do not impact significantly on the overall cost dimension of the company. Curiously, activities and resources tend to change more significantly than the overall cost structure. This may suggest that these companies face changes with impact on operations, but without overall financial impact.

Furthermore, in the right-hand of the BMC, the components $\mathrm{CR}$ and $\mathrm{CH}$ changed much less than most of the other components on the "emotional" side of the BMC, particularly the former. We may ask why these business building blocks do not change so frequently or significantly. Indeed, some of the companies increased the number of communication channels used (e.g., social media, participation in events) but, on the other hand, we also realized that others have been disinvesting in their channels. One may assume that these components were already well established at the beginning of the business and no particular evolution was needed or demanded. But, such inertia may also result from opposite reasons. These two components represent more detailed aspects of the business model that may be develop later or remain underdeveloped in the first years when business effectiveness is predominant. They also ask for additional and specialized skills and knowledge related to marketing and business management that are not priorities in the initial rounds of hiring new collaborators. This kind of successive waves of development in the business model is a very common business strategy where technical skills come first and soft or business skills development happen later. Indeed, the reduced changes in these two important components that we can find in more complete and sophisticated business models may indicate some underdevelopment and limitations that should be mitigated.

As in the case of the $\mathrm{CR}$ component, $\mathrm{CH}$ has evolved slightly more in $\mathrm{BP}$ companies. In general terms, when the three types of companies are compared, OP companies tend to show less significant changes in their business model when compared to BP ones.

\section{The most dynamic components of the BMC}

Firstly, only a few components experienced very significant changes (pivoting) and those were the VP and $\mathrm{CuS}$ dimensions of the business model. The CuS was the right-hand side BMC building block where the most significant changes were observed - and, particularly, in the cases of $\mathrm{BP}$ and $\mathrm{OP} \& \mathrm{BP}$ companies. OP companies are not so agile as $\mathrm{BP}$ ones in changing products and services offered what may result in a higher risk of the business. Indeed, some OP companies are still focus on the same products since the company was launched. Even if OP companies are constantly improving the product, adjusting it to the market 
needs and expectations, those changes are more incremental than radical - e.g., new versions of the initial product.

On the other hand, BP companies are more dynamic, for example, two of these companies made a pivot in their value proposition what represents a radical change of the business model. Furthermore, it was observed in the companies interviewed that, as the value proposition evolved (e.g., with new products or services), new sources of revenue were added to the company's business model which forced changes in this component. There is, therefore, a causal relationship between the value proposition and the sources of revenue. Thus, beyond identifying the causes of changes in business models, also the impact of these changes on the other elements of the business model should be analyzed. This aspect is discussed next.

\section{The most and the less interrelated components of the BMC}

The left-hand components of the BMC related to the rational of the business or the way how the value proposition is produced are apparently more interconnected than the components related to the emotional side of the business model (presented in the right-side of the model) because the components of the latter apparently can change/evolve more independently. The components of the lefthand of the business model (i.e., KA, KR and KP) change in a more interrelated way and more significantly. On one hand, changes in the key resources are essentially related to hiring more collaborators and that occur more often in BP companies. On the other hand, key partnerships, if not established at the beginning tend to only occur much later when the companies have more experience in the market and are able to align them with company's business strategy.

\section{Sources of change and impacts}

A change in a particular BMC component may have an impact on other components. The type of impact that the change in certain BMC components caused in the remaining components was analyzed. It was concluded that:

- A change in a BMC component may not affect the remaining eight components but adjacent components tend also to change;

- All the components on the left-hand side of the BMC (excepting CoS) and the $\mathrm{CuS}$ component on the right-hand were the ones with the greatest impact on the business model of the 15 companies;

- The VP component and all components belonging to the right side of the BMC (excepting $\mathrm{CH}$ ) were the most affected by the changes that have occurred;

- The propagation of an "earthquake" (which are starting points for change and innovation in business models) does not necessarily follow what is suggested by the four epicenters proposed by Osterwalder and Pigneur [4].

\section{Key moments and decisions}

Finally, we highlight the most significant key moments/decisions that were identified as drivers of change in the business model of the studied software startups. They pushed or justified changes in different BMC components. The collected key moments and decisions driving changes in the business model are: 
- Value proposition: innovation, product development;

- Customer segments: the first clients, addressing new (or more) clients, internationalization;

- Customer relationship: acquiring new clients, changing customer relationship;

- Channels: better communication through social networks;

- Revenue streams: venture capital investment, increasing sales;

- Key resources: increasing the number of employees, retaining/attracting experienced employees, hiring skilled employees for specific positions;

- Key activities: changing the software development process, addressing the maintenance of the products, addressing branding and marketing;

- Key partners: changing unsuccessful partnerships, establishing technical partnerships;

- Cost structure: N/A.

Changes in the value proposition and customer segments are related and are those with more impact in the business model representing a major change or pivot. This was the case of companies $\mathrm{A}$ and $\mathrm{N}$.

Initially, the product of Company A had some acceptance and quickly attracted close to 20 customers. However, the product does not solve a real problem from the perspective of the market and sales were not enough to support the expenses of the company. Thus, after a year of its launch, the product was discontinued. Company A had to abandon the first product and decided to redefine its strategy and its business model. With the departure of two shareholders, the company chose to provide web services and web design in order to generate cash flow to finance the investment in its own products and changed the focus to the international market namely, the USA.

Company $\mathrm{N}$ developed an electronic government system and established a contract with four municipalities. However, this happens in the crisis period and under the economic supervision of the Troika in Portugal. As a consequence, all the funding that would have allowed the four municipalities to buy the product was cancelled. Thus, Company $\mathrm{N}$ decided to focus on new business areas in the company namely, an e-commerce solution, a CRM tool, and also web development services. The company decided to develop tailored made software for its customers and a significant restructuring of the business was made.

\subsection{Validity threats}

A series of issues may influence the results of this exploratory study, such as the researchers who performed the study or the observed data set. In the following, we consider the threats to validity, in a way to discuss the acceptance and accuracy of our findings.

The use of the BMC may be criticized. There are multiple models to address the business models of a company, like [17]. However, the BMC is nowadays the most used one and it is particularly popular to support the creation of startups.

We do not claim that our results are representative of all software startups, or to be generalizable to other economic fields. Though, they provide relevant 
insights from a set of software startups. The number of companies is relatively low, even if they the three considered types of companies are equally covered.

During the field study, two researchers were responsible for interviewing the participants, collecting and organizing the data, and processing the results. More than one author drew the conclusions from the gathered data, so there is a risk related to interpretation of the findings. Furthermore, we tried to mitigate this validation threat by the use of a software application for the analysis of qualitative data, with follow-up reports that were sent to the interviewees and by discussing the preliminary results at length with all the researchers.

\section{Conclusions}

For the data collection from the participating software companies, it was necessary to prepare a set of tools that can be used in similar studies. The interview script, based on the list of questions made in the BMC and ELDM, can be used when conducting the interviews in such studies. The data collected through the interviews and web search allowed to form a very thorough and detailed database. The analysis of some of these data may be the starting point for the realization of new studies within the software companies.

For a better understanding of the components that have evolved in different ways in the business model of each company, it was necessary to develop a score system, in the range $0-3$ as shown in Table 2 . This system has allowed the identification of the components that have more and less evolved for each of the three identified groups of companies and can be used in other similar studies.

The four types of epicenters that Osterwalder and Pigneur (2011) present as possible starting points for the innovation of business models were verified when analyzing the data and results. In this study, it was also found that the "quake" propagation does not necessarily follow and that change in a particular component may not affect all adjacent BMC components.

Finally, some opportunities for further work can be highlighted. In-depth case studies can be performed in some of the companies that took part in this study. Another possible opportunity is related to compare the business strategies of mature software companies vs. startups, which in this case implies extending the analysis to more companies (namely, mature ones). Coleman and O'Connor show that the previous experience of the person that manages the development work is the main influencer on the process a company initially uses [18]. This may provide a good trigger to study if the same happens with respect to the business approach followed by startups.

\section{Acknowledgements}

This work was supported by COMPETE: POCI-01-0145-FEDER-007043 and FCT Fundação para a Ciência e a Tecnologia within the Project Scope: UID / CEC / 00319 / 2013. 


\section{References}

1. Eric Ries. The lean startup: How today's entrepreneurs use continuous innovation to create radically successful businesses. Crown Publishing Group, 2011.

2. Henri Terho, Sampo Suonsyrjä, Aleksi Karisalo, and Tommi Mikkonen. Ways to cross the rubicon: Pivoting in software startups. In Pekka Abrahamsson, Luis Corral, Markku Oivo, and Barbara Russo, editors, 16th International Conference on Product-Focused Software Process Improvement (PROFES 2002), volume 9459 of Lecture Notes in Computer Science, pages 555-568. Springer, 2015. DOI 10.1007/978-3-319-26844-6 41.

3. Sohaib Shahid Bajwa, Xiaofeng Wang, Anh Nguven Duc, and Pekka Abrahamsson. How do software startups pivot? Empirical results from a multiple case study. In Andrey Maglyas and Anna-Lena Lamprecht, editors, 7th International Conference of Software Business (ICSOB 2016), volume 240 of Lecture Notes in Business Information Processing, pages 169-176. Springer, 2016. DOI 10.1007/978-3-319-40515514.

4. Alexander Osterwalder and Yves Pigneur. Business model generation: A handbook for visionaries, game changers, and challengers. Wiley, 2010.

5. Sven C. Voelpel, Marius Leibold, and Eden B. Tekie. The wheel of business model reinvention: How to reshape your business model to leapfrog competitors. Journal of Change Management, 4(3):259-276, 2004. DOI 10.1080/1469701042000212669.

6. Derek F. Abell. Defining the business: The starting point of strategic planning. Prentice-Hall, 1980.

7. Constantinos Markides. Strategic innovation. MIT Sloan Management Review, (Spring):9-23, April 1997. DOI URL.

8. Alexander Osterwalder and Yves Pigneur. Modeling value propositions in ebusiness. In 5th International Conference on Electronic Commerce (ICEC 2003), pages 429-436. ACM, 2003. DOI 10.1145/948005.948061.

9. Patrick Stähler. Business models as an unit of analysis for strategizing. In International Workshop on Business Models, Lausanne, Switzerland, pages 4-5, 2002.

10. Rainer Alt and Hans-Dieter Zimmermann. Preface: Introduction to special section - business models. Electronic Markets, 11(1):3-9, 2001. DOI 10.1080/713765630.

11. Roderick van Cann, Slinger Jansen, and Sjaak Brinkkemper. Software business start-up memories: Key decisions in success stories. Palgrave Macmillan, 2013.

12. Linder J. and Cantrell S. Changing business models: Surveying the landscape. Technical report, Accenture - Institute for Strategic Change, May 2000.

13. Peter Wright, Mark J. Kroll, and John A. Parnell. Strategic management: Concepts and cases. Prentice Hall, 4th edition, 1998.

14. Djalma Oliveira. Planejamento estratégico: Conceitos, metodologia e práticas. Atlas, São Paulo, Brazil, 26th edition, 2009. In Portuguese.

15. João M. Fernandes and Ricardo J. Machado. Requirements in engineering projects. Lecture Notes in Management and Industrial Engineering. Springer, 2016. DOI 10.1007/978-3-319-18597-2.

16. Rosalind Edwards and Janet Holland. What is qualitative interviewing? The 'What is?' Research Methods Series. Bloomsbury Publishing, 2013.

17. Ash Maurya. Running lean: Iterate from plan A to a plan that works. O'Reilly Media, 2012.

18. Gerry Coleman and Rory O'Connor. An investigation into software development process formation in software start-ups. Journal of Enterprise Information Management, 21(6):633-648, 2008. DOI 10.1108/17410390810911221. 